\title{
Molecular study on genital wart patients in Babylon province-Iraq
}

Israa Abbas Mahdi Al Saadi ${ }^{1}$; Mohammed A.K. Al Saadi ${ }^{*}$; Wisam A.A. Ewadh

The aim of this study was to molecular identification of HPV genotypes in genital wart patients in their blood samples in Babylon province-Iraq. This work was applied on (40) genital wart patients admitted to the outpatient department of Dermatology and Venereology in Merjan Medical City, Hilla-Iraq and private clinic during the period from November (2013) to March (2014). The patients consist of (16 males and 24 females) with their age range (2-48) years, while (20) apparently health controls which consist of (males and females) with age range approximately matched to genital wart patients. Blood samples were collected from both patients and controls to identify the genotypes of HPV by molecular methods by polymerase chain reaction (PCR). The results of this study showed (15\%) positive for HPV genotypes. The positive results of HPV genotypes were (high risk group) for this virus.

Keywords: HPV; Genital wart; Polymerase chain reaction; Molecular methods

*Corresponding Author: Mohammed A.K. Al-Saadi:

${ }^{1}$ College of Medicine

Babylon University

Received 03 August 2014; accepted 04 October 2014

Copyright (C) 2014 M.A. et al. This is article distributed under the terms of the Creative Commons Attribution License (http://creativecommons.org/licenses/by/2.0), which permits unrestricted use, distribution, and reproduction in any medium, provided the original work is properly cited.

\section{Introduction}

Human papillomaviruses (HPVs) are a group of more than (150) related viruses. Each HPV virus in the group is given a number. HPVs are called papilloma viruses because some of the HPV types cause warts or papillomas, which are non-cancerous tumors [1]. Human Papillomavirus (HPV) is the single most important pathogen of the lower genital tract. Human Papillomaviruses cause benign and malignant lesions of the cervical, vaginal, vulvar, and penile mucosa and skin [2].

HPVs are epitheliotropic DNA viruses that are typed based on their DNA sequence and subgrouped into cutaneous and mucosal types, with the latter group further subclassified into low and high oncogenic risk types [3]. The papilloma viruses are 
attracted to and are able to live only in squamous epithelial cells in the body. Squamous epithelial cells are thin, flat cells. They are found in the surface of the skin and in moist surfaces like the vagina, anus, cervix, vulva,head of the penis, mouth, throat, trachea, bronchi, and lungs. HPVs will not grow in other parts of the body [4]. Most HPV infections are asymptomatic and do not result in epithelial changes, therefore, they are not detected by either visual exam or by cytologic screening tests (Pap tests).

HPV infections are common, and the prevalence of cutaneous viral warts is (5$23 \%$ ) in children [5]. The high peak of HPV prevalence in (20-24) years-old is related to sexual debut, while the subsequent decrease in prevalence reflects the acquisition of immunity and monogamous relationships [2]. Warts, benign HPV-induced lesions, usually regress spontaneously within several months. Immunodeficiency predisposes to persistent HPV infections and the development of generalized verrucosis [5].

HPV infections are the most common sexually transmitted infections in the United States. In fact, more than half of sexually active people are infected with one or more HPV types at some point in their lives [6].

Regarding Babylon governorate, Iraq, no previous studies dealing the occurrence of HPV in patients with genital warts. Thus the objective of this work was detection of HPV (high risk) Genotypes (16, 18, 31, 33, 35, 39, 45, 51, 52, 56, 58, 59 and 68) in blood samples of genital wart patients.

\section{Method}

\section{Clinical samples}

A total of (40) patients with genital wart consisting of (24) females and (16) males were involved in this study. The patient's age ranged from (2-48) years. All genital wart cases were clinically diagnosed by a specialist Dermatologist clinician. These patients were admitted to the outpatient department of Dermatology and Venereology in Merjan Medical City, Hilla-Iraq and private clinic during the period from November (2013) to March (2014). Patients with suffering from other diseases in addition to GW were excluded. The necessary ethical approval from the hospitals and private clinics were obtained. Moreover, all subjects involved in this work were informed and the agreement required for doing the experiments and publication this work was obtained from each one prior the collection of samples. 
A total of (20) apparently healthy subjects of both sexes were involved as a control groups. The age range of controls was approximately matched to genital wart patients (10-40) years.

Blood samples were collected from both patients and controls a volume of five milliliters of venous blood was withdrawn by disposable syringe under aseptic technique (7). Each blood sample was divided into two parts:

A. Two milliliters were put in a tube containing anti-coagulant (EDTA) for checking Blood group test.

B. Three milliliters were placed in a sterile plane tube and allowed to clot, and then serum was separated by centrifugation at (3000) rpm for (10) minutes. The serum has been stored by deep freezing $\left(-20^{\circ} \mathrm{C}\right)$ until used for required test. To identify the genotypes of HPV (high risk) by molecular techniques by polymerase chain reaction (PCR) according to the manufacturer instructions of Promega company.

\section{Results and Discussion}

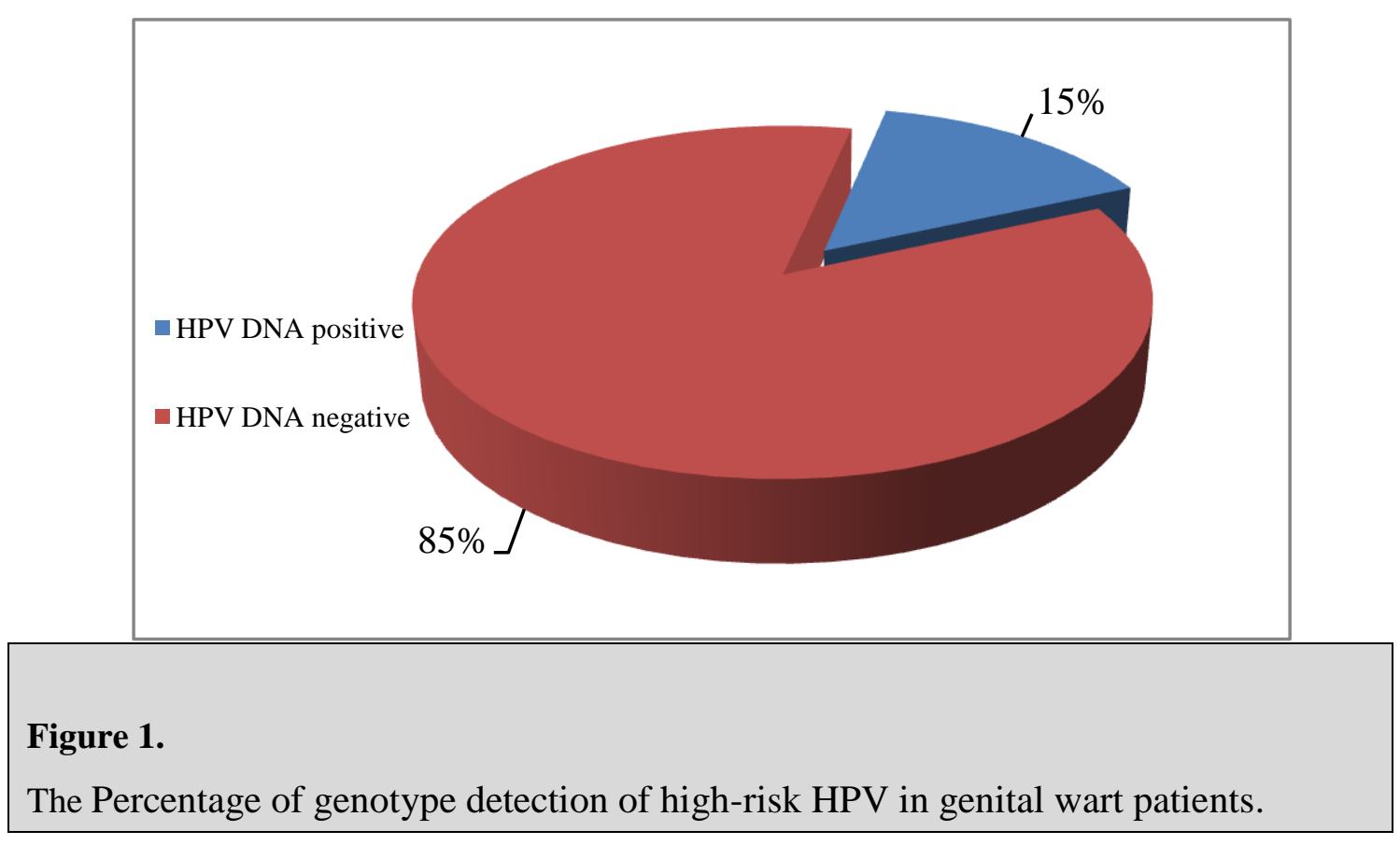




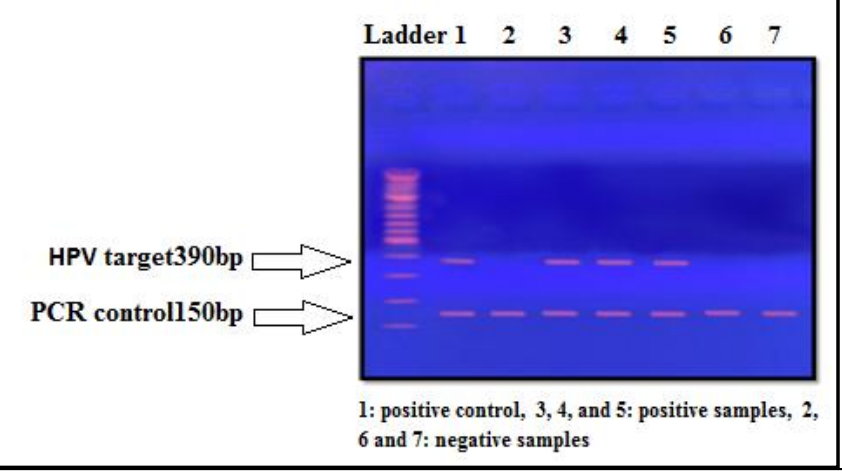

Figure 2.

Gel electrophoresis of PCR product of high-risk HPV genotypes

Among the (40) clinical samples of genital wart, only $6(15 \%)$ gave positive for high-risk HPV DNA, whereas 34 (85\%) gave negative results, Figure (1) and Figure (2). This is the first study in Iraq conferring the genetic detection of high risk-HPV in blood of genital wart patients in Babylon-province/Iraq.

These results suggested that HPV cannot be transferred only by skin contact, sexual intercourse and by other non-sexual transmission such as vertical transmission and perinatal transmission but also by blood. These results are in agreement with [8] who found that $(8.3 \%)(15 / 180)$ from healthy Australian male blood donors to be HPV DNA positive and a wide variety of different of HPV-types were isolated from the peripheral blood mononuclear cells (PBMCs).

Half of the HPV types detected in the PBMCs were skin HPV types that are commonly found in asymptomatic infection of normal, healthy skin [9, 10].The rest were high-risk HPV types that are associated with cancer development were detected in $1.7 \%(3 / 180)$ of the samples. HPV is estimated to cause $3-5 \%$ of all human cancers [11]. Further, it had reported that human papillomavirus (HPV)-DNA can be found in circulating blood, including PBMCs, sera, plasma and arterial cord blood.

The Majority of external genital warts are caused by HPV types (6) and (11) which are not associated with significantly increased risk of neoplastic transformation. However, (10\%) of genital warts are caused by HPV types (16) and (18) and these types are associated with an increased risk of cervical vaginal, vulval and penile carcinoma and anal, oral, oropharyngeal cancers [13]. 
Detection of HPV types $(6,11,16$ or 18$)$ has often been interpreted as an indication of sexual or vertical transmission (from mother to new born), whereas the presence of skin HPV types would rather implicate hetero-or auto inoculation [14]. HPV DNA has been also found in the genital tract of newborns. Within three days after delivery, HPV DNA detection varied from $(0 \%)$ to $(53 \%)[15,16]$. HPV DNA was only detected in blood when PBMCs were analyzed and had not been treated with trypsin.

Therefore, HPV appears to be attached to the PBMCs by a cell surface protein. It has previously been shown that PV virions can bind to a wide range of cell types from different species [17], and these data suggest that HPV is attached to the cell surface of the PBMCs and is not taken up by the cell alpha 6 integrin receptors (which found in $\mathrm{T}$ cell and platelets) which have been suggested to bend and mediate uptake of the virus particles into the cell $[18,19]$.

However the serum and (T) cell fractions in the study of healthy Australian male blood donors were HPV negative. A widespread distribution of different HPV types in various blood cell types, suggesting that the HPV virions tend to attach more to some types of PBMCs than others [8]. Other study showed that glycosaminoglycans are able to bind HPV with low affinity [20]. Furthermore, to identify which specific receptors mediate the uptake of HPV into peripheral blood is important.

However the presence of HPV DNA in blood, including high risk HPV types, suggest that further studies are needed to elucidate whether HPV virions can be transmitted through blood transfusion, furthermore, the potential of blood being the vehicle for HPV to infect another body organs has still yet to be determined [8]. Some early studies have reported the presence of HPV DNA in peripheral blood mononuclear cells; therefore blood transfusion could be a source of acquired PBMC HPV-DNA [12]. HPV DNA has also been detected in banked, frozen blood cells from pediatric HIV patients and in fresh blood cells from healthy donors [21].

Using sensitive polymerase chain reaction (PCR)-based detection, normalappearing skin surrounding HPV-associated lesions and even skin of healthy volunteers may contain HPV DNA. These observations help to explain the high recurrence rate of warts (e.g. 20-50\% for genital condylomata) and the observation that treatment may not prevent further transmission of the virus. The highly sensitive 
PCR has revealed apparently very high rates of HPV cervical infection in the general population [22].

Longitudinal studies have suggested that many infections are transient and individuals may lose or acquire different HPV types over time but persistent, high-grade HPV infection in the cervix is a risk factor for the development of cervical intraepithelial neoplasia $[23,24]$.

More than $(2 \%)$ of the women tested positive for $\mathrm{HPV}_{16}, \mathrm{HPV}_{18}$, or both, strains of the virus known to cause cervical cancer. High-risk strains of HPV are found in 99\% of women with cervical cancer [25]. HPV16 is the type more likely to progress and becomes more severity of lesions than other HPV types [26].

Most HPV infections are transient and are eliminated by the immune response over the course of months. Typically, (50\%) of HPV infections clear within 8-months and $(90 \%)$ of infections are cleared within 2-years [27, 28].

In conclusion, The duration of the infection is also related to HPV type. On average, infections with high oncogenic risk HPVs last longer than infections with low oncogenic risk HPVs, 13-months versus 8-months, respectively. Persistent infection with high oncogenic risk HPVs increases the risk of development of premalignant lesions and subsequent carcinoma [2].

\section{Competing interests}

The authors declare that there is no conflict of interest.

\section{Author Contributions}

All authors wrote, read and approved the final manuscript.

\section{References}

1. Kiprono SJ, Erick A, Titus SK. Knowledge, Attitude and Practices of Students Enrolled in Health Related Courses at Saint Louis University towards Human Papillomavirus (Philippines). Journal of Natural Sciences Rese 2012; 2(6): 48-54.

2. Pirog E. Molecular markers and HPV detection in the diagnosis of lower genital tract lesions. PhD thesis. De. Vrije Universities Amsterdam 2011.

3. zur Hausen H. Papillomaviruses in the causation of human cancers - a brief historical account. Virology 2009;384(2):260-5 
4. American Cancer Society. (2013). Human papilloma virus (HPV), Cancer, HPV testing, and HPV vaccines: Frequently asked questions.

5. Leiding JW, Holland SM. Warts and all: human papillomavirus in primary immunodeficiency. J. Allergy. Clin. Immunology 2012;130: 1030-48.

6. CDC .Genital HPV Infection 2013.

7. Bain B, Bates I, Laffan M, S. Lewis. Dacie and Lewis Practical Haematology, 11th Edition. 2012, Churchill Livingstone, London.

8. Che -Ha Chen A, Keleher A, Mary-Anne K, et al. Human papillomavirus DNA detected in peripheral blood samples from healthy Australian male blood donors. Prostate Cancer Foundation in Australia.

9. Antonsson A, Forslund O, Ekberg H, Sterner G, Hansson BG. The ubiquity and impressive genomic diversity of human skin papillomaviruses suggest a commensalic nature of these viruses. $J$ Virol 2000;74(24):11636-41.

10. Chen AC1, McMillan NA, Antonsson A. Human papillomavirus type spectrum in normal skin of individuals with or without a history of frequent sun exposure. J Gen Virol 2008;89(Pt 11):2891-7.

11. Parkin DM. The global health burden of infection-associated cancers in the year 2002. Int J Cancer 2006;118(12):3030-44.

12. Bodaghi S1, Wood LV, Roby G, et al. Could human papillomaviruses be spread through blood? J Clin Microbiol 2005;43(11):5428-34.

13. Gearhart PA. Human Papillomavirus, 2012 Medscape.

14. Syrjänen S. Current concepts on human papillomavirus infections in children. APMIS 2010;118(6-7):494-509.

15. Kaye JN1, Cason J, Pakarian FB, et al. Viral load as a determinant for transmission of human papillomavirus type 16 from mother to child. J Med Virol 1994;44(4):415-21.

16. Smith EM1, Johnson SR, Cripe T, et al. Perinatal transmission and maternal risks of human papillomavirus infection. Cancer Detect Prev 1995;19(2):196-205.

17. Roden RB1, Kirnbauer R, Jenson AB, Lowy DR, Schiller JT. Interaction of papillomaviruses with the cell surface. $J$ Virol 1994;68(11):7260-6.

18. Evander M, Frazer IH, Payne E, Qi YM, Hengst K, McMillan NA. Identification of the alpha6 integrin as a candidate receptor for papillomaviruses. J Virol 1997;71(3):2449-56. 
19. Wang SS, Hildesheim A. Chapter 5: Viral and host factors in human papillomavirus persistence and progression. J Natl Cancer Inst Monogr 2003; 31:3540.

20. Drobni P, Mistry N, McMillan N, Evander M. Carboxy-fluorescein diacetate, succinimidyl ester labeled papillomavirus virus-like particles fluoresce after internalization and interact with heparan sulfate for binding and entry.Virology 2003;310(1):163-72.

21. Pao CC, Lin SS, Lin CY, Maa JS, Lai CH, Hsieh TT. Identification of human papillomavirus DNA sequences in peripheral blood mononuclear cells. Am J Clin Pathol 1991;95(4):540-6.

22. Burns T, Breathnach S, Cox N, Griffiths C. (2010). Rook's Text book of Dermatology. Volum1 8th ed. Wiley-Blackwell. U.K.

23. Liaw KL1, Glass AG, Manos MM, et al. Detection of human papillomavirus DNA in cytologically normal women and subsequent cervical squamous intraepithelial lesions. J Natl Cancer Inst 1999;91(11):954-60.

24. Woodman CB1, Collins S, Winter H, et al. Natural history of cervical human papillomavirus infection in young women: a longitudinal cohort study. Lancet 2001;357(9271):1831-6.

25. Dunne EF, Unger ER, Sternberg M, et al. Prevalence of HPV infection among females in the United States. JAMA 2007;297(8):813-9.

26. Banura C. Human papillomavirus infections among sexually active young women in Uganda: Implications for a vaccination strategy. PhD thesis. 2009 Makerere University.

27. Franco EL, Villa LL, Sobrinho JP, Prado JM, Rousseau MC, Désy M, Rohan TE. Epidemiology of acquisition and clearance of cervical human papillomavirus infection in women from a high-risk area for cervical cancer. J Infect Dis 1999;180(5):1415-23.

28. Wheeler CM. Natural history of human papillomavirus infections, cytologic and histologic abnormalities, and cancer. Obstet Gynecol Clin North Am. 2008;35(4):51936; vii. 